\author{
В.М. Тонконогий, д-р техн. наук, А.А. Якимов, д-р техн. наук, \\ Л.В. Бовнегра, канд. техн. наук, \\ Л.В. Майзлис, А.С. Филанович, Одесса, Украина

\section{ИССЛЕДОВАНИЕ ДИНАМИЧЕСКИХ ЯВЛЕНИЙ, ПРОИСХОДЯЩИХ ПРИ ПРЕРЫВИСТОМ ШЛИФОВАНИИ}

\begin{abstract}
Аннотация. Применение шлифовальных кругов на поверхностях, которых имеются прорези, позволяет снизить тепловыделение в зоне резания. Целью научного исследования является определение условий создания в упругой системе станка колебаний, способствуюших самозаточке режущего микрорельефа прерывистого круга, и возникновения ударного $и$ параметрического резонансов. Выявлены условия прерывистого шлифования, при которых в упругой системе плоскошлифовального станка не возникают ударный и параметрический резонансы и появляется возможность самооформления режущего микрорельефа рабочей поверхности абразивного инструмента в прочессе его работы.
\end{abstract}

Ключевые слова: режущий выступ, упругая система станка, прерывистый круг, параметрический резонанс, упругий резонанс, рабочая поверхность круга, микрорельеф круга.

Введение и постановка проблемы. Шлифование является наиболее распространенным методом окончательной обработки закаленных деталей. обеспечивающий высокую точность их изготовления. Однако процесс шлифования сопровождается значительным тепловыделением, следствием которого является появление на обработанных поверхностях прижогов, трещин и вредных растягивающих напряжений. Один из путей снижения теплообразования в зоне резания является применение шлифовальных кругов с прерывистой рабочей поверхностью. Однако при прерывистом шлифовании в упругой системе станка возникают колебания, способные при определенных условиях перерасти в ударный и параметрический резонансы. При расчетах длин режущих выступов и впадин на рабочей поверхности шлифовального круга стремятся обеспечить главным образом требуемую степень понижения температуры в зоне резания и не учитывают динамические явления, сопровождающие процесс прерывистого шлифования.

Анализ последних достижений и публикаций. Изучению колебаний, возникающих при шлифовании, посвящены работы [1-5]. Но эти работы не связаны с прерывистым шлифованием. В работе [6] выявлены условия образования волнистости при плоском прерывистом шлифовании переферией круга. Вместе и тем роль параметрических колебаний в формировании волнистости обрабатываемой поверхности не выявлена.

(ㄷ В.М. Тонконогий, А.А. Якимов, Л.В. Бовнегра, Л.В. Майзлис, А.С. Филанович, 2019 
Малоизученность динамических явлений, сопровождающих процесс шлифования прерывистыми кругами, сдерживает широкое применение этих кругов на машиностроительных предприятиях.

Цель работы - на основе изучения динамических явлений, сопровождающих процесс прерывистого шлифования, определить условия предотвращения возникновения в упругой системе плоскошлифовального станка ударного и параметрического резонансов, и выявить возможность использования колебаний для самозаточки режущих зерен на рабочей поверхности абразивного инструмента.

Изложение основного материала. Энергоемкость процесса шлифования зависит от распределения работ, затрачиваемых на резание и трение.

При движении режущего зерна круга со скоростью $V_{K R}$ возникает тангенциальная сила резания $P_{Z}$, которую можно представить в виде

$$
P_{Z}=P_{Z T R}+P_{Z R E Z},
$$

где $P_{Z}$ и $P_{Z R E Z}$ соответственно составляющие тангенциальной силы

$$
\begin{gathered}
P_{Z T R}=f \cdot F_{y} ; \\
P_{Z \text { REZ }}=\sigma \cdot S .
\end{gathered}
$$

где $f$ - коэффициент трения зерна с обрабатываемым материалом;

$\sigma$ - условное напряжение резания, $N / m^{2}$;

$\mathrm{S}$ - площадь сечения стружки, $m^{2}$.

Из работы Новикова Ф.В. [7] известно, что

$$
P_{Z R E Z}=\frac{2 \cdot \sigma_{S Z}}{K_{S H ~ R E Z}} \cdot S,
$$

где $\sigma_{S Z}$ - предел прочности материала на сжатие, $\mathrm{N} / \mathrm{m}^{2}$.

После подстановки выражений (2) и (4) в уравнение (1), получим

$$
P_{Z}=f \cdot P_{y}+\frac{2 \cdot \sigma_{S Z}}{K_{S H R E Z}} \cdot S .
$$

Разделив слагаемые (5) на $P_{y}$, получим

$$
K_{S H}=f+\frac{2 \cdot \sigma_{S Z}}{K_{S H R E Z} \cdot P_{y}} \cdot S \cdot
$$

Преобразуем зависимость (6) к виду 


$$
P_{Y}=\frac{2 \cdot \sigma_{S Z} \cdot S}{\left(K_{S H}-f\right) \cdot K_{S H ~ R E Z}}=\frac{2 \cdot \sigma_{S Z} \cdot S}{\left(K_{S H}-f\right)^{2}} .
$$

Принимая суммарную площадь среза всеми работающими зернами $\mathrm{S}$ в виде отношения производительности Q к скорости резания $V_{K R}$, зависимость (7) можно представить в виде

$$
\mathrm{Q}=\frac{P_{Y} \cdot V_{K R} \cdot\left(K_{S H}-f\right)^{2}}{2 \cdot \sigma_{S Z}} .
$$

В зависимости (8), наряду с параметрами режима шлифования $P_{Y}$ и $V_{K R}$ входит физический параметр $K_{S H}$, который, в свою очередь, зависит от режимов шлифования. Следовательно, производительность шлифования имеет неоднозначную взаимосвязь с режимом обработки. С увеличением $P_{Y}$ и $V_{K R}$ производительность обработки линейно возрастает. С другой стороны, с увеличением $P_{Y}$ и $V_{K R}$ изменяется параметр $K_{S H}$, что искажает линейный характер зависимости $Q=f\left(P_{Y}, V_{K R}\right)$.

Таким образом, анализируя зависимость (8), можно сделать вывод о том, что на производительность шлифования оказывают большое влияние физические факторы, которые обобщенно описываются параметром $K_{S H}$, причем этот параметр входит в зависимость (8) не в «чистом виде», а в виде квадрата разности $\left(K_{S H}-f\right)^{2}$, который может изменяться в весьма широких пределах от нуля (случай перехода от процесса трения к процессу резания, когда $\left(K_{S H}=f\right)$ до значений $0,5 \ldots 0,7$ (случай высокопроизводительного шлифования, когда $\left.K_{S H}>>f\right)$. Соответственно в широких пределах будет изменяться и производительность обработки Q. Например, по мере износа зерен и затупления круга, что соответствует условию $K_{S H} \rightarrow f$, производительность обработки будет уменьшаться до нуля. Это указывает на то, что разность $\left(K_{S H}-f\right)$ - величина, весьма чувствительная к изменению $K_{S H}$, особенно, когда $K_{S H}$ мало отличается от $f$.

Из приведенного анализа выражения (8) следует, что производительностью шлифования можно управлять на основе оптимизации параметра $K_{S H R E Z}$. Увеличить параметр $K_{S H R E Z}$ или стабилизировать его во времени можно, во-первых, за счет режима, обеспечивающего 
самозатачивание круга путем непрерывной его правки, а во-вторых, за счет снижения интенсивности износа режущих зерен круга. Это достигается путем применения высокопрочных режущих материалов, смазочноохлаждающих жидкостей, твердых смазок, импрегнирования шлифовальных кругов, применения прерывистых кругов.

Уравнение для определения общей энергоемкости процесса шлифования имеет вид

$$
\frac{f \cdot P_{Y} \cdot V_{K R}}{Q \cdot \sigma}+\frac{2 \sigma_{S Z}}{\left(K_{S H}-f\right) \cdot \sigma}=1 .
$$

С учетом выражения $\sigma=\frac{2 \cdot \sigma_{S Z} \cdot K_{S H}}{K_{S H R E Z}}$ и некоторых преобразований (9), получим

$$
\frac{f}{K_{S H}}+\left(1-\frac{f}{K_{S H}}\right)=1
$$

Уравнение (10) характеризует закон сохранения энергии при шлифовании. По мере затупления шлифовального круга уменьшается $K_{S H}$. В выражении (10) при возрастании первого слагаемого второе слагаемое пропорционально уменьшается.

При $K_{S H}=f$ первое слагаемое стремится к единице, а второе - к нулю.

Связь параметра $K_{S H R E Z}$ с физическим параметром $\eta$, характеризующим износ режущих зерен, выражается зависимостью

$$
\eta=1-\frac{\pi \cdot \operatorname{tg} \gamma \cdot H V}{4 \cdot \sigma_{S Z}} \cdot K_{S H R Z}^{2}
$$

где $\gamma$ - угол при вершине режущего зерна;

$H V$ - твердость по Виккерсу обрабатываемого материала, $N / m^{2}$.

В табл. 1 представлены экспериментальные значения тангенциальной составляющей силы резания $P_{Z}$ при шлифовании по упругой схеме плоских образцов из стали $12 \mathrm{X} 2 \mathrm{H} 4 \mathrm{~A}\left(\sigma_{S Z}=3600 \mathrm{MPa}\right)$ кругом 24А25С16К5.

По экспериментальным данным рассчитывались параметры $\sigma u K_{S H}$. За пятиминутный период шлифования глубина резания уменьшилась в 12 раз, условное напряжение резания $\sigma$ возросло в 5,8 раза; тангенциальная составляющая силы резания $P_{Z}$ уменьшилась в 1,9 раза.

Как видно, интенсивность уменьшения съема металла не коррелирует ни с одним из указанных технологических параметров. 
Таблица - Влияние времени обработки на параметры шлифования (условия проведения эксперимента $\mathrm{Vkr}=29,6 \mathrm{~m} / \mathrm{s}, V_{S T}=6 \mathrm{~m} / \mathrm{min}$ (скорость стола) Ру=60N)

\begin{tabular}{|c|c|c|c|c|c|c|c|c|c|c|c|}
\hline \multirow{2}{*}{$\begin{array}{r}\text { № } \\
\text { экс } \\
\text { пер } \\
\text { име } \\
\text { нта }\end{array}$} & \multirow{2}{*}{$\begin{array}{c}\text { Время } \\
\text { обраб } \\
\text { отки, } \\
\min \end{array}$} & \multirow{2}{*}{$\begin{array}{c}\text { Глубина } \\
\text { шлифова } \\
\text { ния за } 5 \\
\text { проходов, } \\
\text { min }\end{array}$} & \multicolumn{3}{|c|}{ Сила резания, N } & \multirow[b]{2}{*}{$\mathrm{K}_{\mathrm{SH}}$} & \multirow[b]{2}{*}{$\begin{array}{r}\sigma \times 10_{4} . \\
\mathrm{Mpa}\end{array}$} & \multirow[b]{2}{*}{$\mathrm{f}$} & \multirow[b]{2}{*}{$\begin{array}{c}\mathrm{K}_{\mathrm{SH}} \\
\mathrm{REZ}\end{array}$} & \multirow[b]{2}{*}{$\eta$} & \multirow[b]{2}{*}{$\begin{array}{c}\mathrm{f} / \mathrm{K}_{\mathrm{S}} \\
\mathrm{H}\end{array}$} \\
\hline & & & $\begin{array}{c}\mathrm{Pz} . \\
10\end{array}$ & $\begin{array}{c}\mathrm{Pz}_{\text {REZ }} \\
10\end{array}$ & $\begin{array}{l}\mathrm{Pz} \\
\text { TR. } \\
10\end{array}$ & & & & & & \\
\hline 1 & 0,1 & 0,036 & 2,9 & 1,94 & 0,94 & 0,48 & 3,24 & 0,153 & 0,324 & 0,458 & 31,9 \\
\hline 2 & 0,5 & 0,013 & 2,2 & 1,16 & 1,08 & 0,373 & 7,2 & 0,18 & 0,193 & 0.748 & 48,2 \\
\hline 3 & 1 & 0,08 & 2,2 & 0,91 & 1,24 & 0,167 & 11,2 & 0,206 & 0,152 & 0,878 & 57,5 \\
\hline 4 & 2 & 0,06 & 1,8 & 0,79 & 1 & 0,299 & 12,4 & 0,167 & 0,132 & 0,911 & 55,9 \\
\hline 5 & 3 & 0,05 & 1,6 & 0,72 & 0,92 & 0,273 & 13,7 & 0,153 & 0,12 & 0,925 & 56 \\
\hline 6 & 5 & 0,03 & 1,5 & 0,6 & 0,93 & 0,256 & 18,8 & 0,157 & 0,1 & 0,948 & 61,3 \\
\hline
\end{tabular}

Для условий шлифования $\operatorname{tg} 60^{\circ}=1,723, \sigma_{S Z}=3600 \mathrm{MPa}, H V=1400 \mathrm{MPa}$ были произведены расчеты $f, f / K_{S H}, \boldsymbol{\eta}$.

В зависимости от затупления абразивного круга доля энергии, затрачиваемая на трение $f / K_{S H}$ изменяется от 31,9 до $61,3 \%$; параметр $K_{S H}$ уменьшается от 0,323 до 0,100 ; коэффициент трения изменяется незначительно от 0,153 до 0,206, а производительность Q уменьшается в 10 раз. Полученные данные позволяют рассматривать процесс шлифования как результат наложения переменного во времени процесса трения режущих зерен и связки об обрабатываемый материал и процесса резания. По мере затупления зерен шлифовального круга увеличивается температура, уменьшается $K_{S H ~ R E Z}$ и возрастают условное напряжение $\sigma$ и параметр $\eta$.

После 30 секундного периода шлифования по упругой схеме круг полностью теряет свои режущие свойства. За это время параметр $\eta$ увеличивается с 0,456 до 0,800 , а условное напряжение резания увеличивается с 32400 до $72000 \mathrm{MPa}$ К Как видно, существует большой резерв повышения эффективности процесса шлифования за счет изыскания способов уменьшения параметра $\eta$.

Для управления режущей способностью кругов и теплонапряженностью необходимо установить функциональную связь между нагрузкой, 
действующей на отдельное зерно, и величиной линейного износа зерна до момента его объемного разрушения или выпадения из связки без разрушения.

В условиях установившегося процесса шлифования величина нагрузки, действующей на максимально выступающее зерно, должна принимать значение, равное или соизмеримое с прочносью зерна на раздавливание или прочностью удержания его в связке, а величина линейного износа зерна значение, соответствующее образованию на рабочей поверхности прерывистого круга энергетически равновесного режущего рельефа. Исходя из этого, в качестве условия оптимизации следует принимать нагрузку, действующую на максимально выступающее зерно, а в качестве оптимизирующего параметра величину его линейного износа. После формирования фронтальной поверхности на режущих выступах прерывистого круга нагрузка, дейсвующая на зерно, в соответствии с прочностными свойствами зерен будет оставаться постоянной независимо от усповий обработки, а величина линейного износа зерна будет выражать взаимосвязь входных параметров (режимов шлифования, характеристики круга, жесткости технологической системы и т.д.) с выходными параметрами (производительностью и качеством обработки, себестоимостью обработки, силами и температурой резания). Например, мягкие круги M1, M2, M3 работают в режиме интенсивного самозатачивания; твердые С1, СТ1 работают в режиме затупления режущих зерен. Следует заметить, что в обоих случаях технологический резерв работы режущих зерен полностью не используется.

В первом случае режущие зерна, не достигнув критического значения затупления, вырываются из связки.

Во втором случае обновления режущих зерен не происходит, зерна изнашиваются, уменьшая тем самым режущую способность кругов (табл.1) и вызывая необходимость частой правки кругов.

Для обеспечения условий самозатачивания твердого круга необходимо шлифование осуществлять с оптимальными значениями параметра $\mathrm{X}$ (износ максимально выступающего зерна) и $\mathrm{P}$ (нагрузка, при которой происходит разрушение зерна или выпадение его из связки). Однако, реализовать условия самозатачивания кругов высокой твердости весьма сложно, так как они интенсивно засаливаются и быстро теряют режущую способность.

Чтобы создать условия для самозатачивания высокотвердых кругов, необходимо в зону резания ввести дополнительную энергию.

Процесс шлифования, при котором при определенных условиях совмещаются интенсивный съем металла с правкой круга, можно осуществить при шлифовании кругами, имеющими на рабочей поверхности ряд чередующихся выступов и впадин строго определенной протяженности. При прерывистом шлифовании возникают вынужденные (периодические с 
разрывом контакта круга) колебания. Наличие колебаний в направлении нормали круга создает условия для максимального внедрения режущих зерен круга в металл. Под воздействием динамической нагрузки, которая воспринимается режущими зернами, расположенными на передней кромке выступа, наблюдается интенсивное осыпание зерен с формированием фронтальной поверхности на режущих выступах.

По мере формирования фронтальной поверхности нагрузка, приходящаяся на зерна режущего выступа, выравнивается.

При прерывистом шлифовании с изменением условий шлифования изменяются угол наклона фронтальной поверхности и линейная ее протяженность в пределах длины режущего выступа.

Величина линейного износа зерен до момента их объемного разрушения поддерживается автоматически самим прдоцессом прерывистого шлифования за счет изменения угла наклона фронтальной поверхности режущего выступа.

Для установления связи динамических явлений с выходными показателями процесса прерывистого шлифования (производительность, теплонапряженность, сила резания и др.) рассмотрим колебания одномассовой системы (шлифовальный круг на упругой подвеске с затуханием), на которую извне со стороны детали действует импульсная вертикальная нагрузка $F\left(\tau_{1}\right)$, где $\tau_{1}$ - период контакта режущего выступа прерывистого круга с обрабатываемой деталью; $\tau_{2}-$ период прерывания процесса резания при прохождении впадины круга над деталью. Колебательное движение массы за период действия силы (за период работы режущего выступа $\tau_{1}$ ) описывается дифференциальным уравнением [8].

$$
m \ddot{y}+c y=F .
$$

За период прохождения впадины круга $\tau_{2}$ движение массы описывается уравнением

$$
m \bar{y}+c y=0 .
$$

Решение (12) имеет вид $y_{1}=A \sin k \tau+B \cos k \tau+y_{S T}$, где $k=\sqrt{\frac{c}{m}}-$ собственная частота колебаний системы; $y_{S T}=\frac{F_{0}}{c}-$ статическое перемещение массы $\boldsymbol{m}$ под действием силы $F_{0}$.

Решение (13) имеет вид $y_{1}=C \sin k \tau+D \cos k \tau$. 
Неизвестные постоянные А, В, C, D определяются из четырех начальных условий

$$
\left.\begin{array}{r}
y_{1}(0)=y_{2}\left(\tau_{2}\right) \\
\dot{y}_{1}(0)=\dot{y}_{2}\left(\tau_{2}\right) \\
y_{1}\left(\tau_{1}\right)=y_{2}\left(\tau_{1}\right) \\
\dot{y}_{1}\left(\tau_{1}\right)=\dot{y}_{2}\left(\tau_{1}\right)
\end{array}\right\}
$$

После решения системы уравнений и некоторых преобразований, получим

$$
\begin{gathered}
C=y_{S T \cdot} \cdot \frac{\sin k \frac{\tau_{1}}{2} \cdot \sin \frac{\tau_{1}+\tau_{2}}{2},}{\sin \frac{\tau_{2}}{2}} \\
D=\frac{y_{S T} \cdot \sin k \frac{\tau_{1}}{2}}{\cos k \frac{\tau_{2}+2 \tau_{1}}{2} \sin \frac{\tau_{2}}{2}}\left(\cos k \frac{\tau_{1}}{2}-\sin k \frac{\tau_{1}-\tau_{2}}{2} \sin \frac{\tau_{2}+2 \tau_{1}}{2}\right), \\
A=C \cdot \cos k \tau_{2}+D \sin k \tau_{2}, \\
B=C \cdot \sin k \tau_{2}+D \cdot \cos k \tau_{2}-y_{c m}
\end{gathered}
$$

При $\sin k=\frac{\tau_{2}}{2}=0$ и $\cos k=\frac{\tau_{2}+2 \tau_{1}}{2}=0$ постоянные А.В,С,D стремятся к бесконечности. При этих условиях в системе наступает ударный резонанс (параметры $y_{1} \rightarrow \infty, y_{2} \rightarrow \infty$ ).

Условия ударного резонанса:

$1 . \sin \left(k \cdot \frac{\tau_{2}}{2}\right)=0$ при $\mathrm{k} \cdot \frac{\tau_{2}}{2}=\pi \cdot n$, где $\mathrm{n}=1,2, . .$, . откуда

$$
\tau_{2}=\frac{2 \cdot \pi \cdot n}{k} .
$$

2. $\cos \left(k \cdot \frac{\tau_{2}+2 \tau_{1}}{2}\right)=0$; при $k \cdot \frac{\tau_{2}+2 \tau_{1}}{2}=\frac{\pi}{2}+\pi \cdot n$, откуда

$$
\tau_{2}+2 \tau_{1}=\frac{\pi \cdot(1-2 n)}{2 k}
$$

Из полученных уравнений (20) и (21) следует бесчисленное множество резонансных состояний системы. Полное решение дифференциального уравнения одномассовой системы имеет вид: 


$$
A=\frac{S}{2 \cdot m \cdot \sqrt{\frac{c}{m}} \cdot \sin \left(\frac{\pi \cdot \sqrt{\frac{c}{m}}}{\omega_{1}}\right)}
$$

где $S=\int_{0}^{\tau} P(\tau) d \tau-$ импульс силы, $k=\sqrt{\frac{c}{m}} ; S=F_{0} \tau_{1}, F_{0}-$ сила резания, $N$; $\omega_{1}$ - угловая частота действия импульсов силы.

Отношение $S$ определяет максимальное отклонение $A$, вызванное

$$
m \sqrt{\frac{c}{m}}
$$

однократным импульсом. Выражением

$$
\beta=\frac{1}{2 \cdot\left[\sin \left(\pi \cdot \frac{\sqrt{\frac{c}{m}}}{\omega_{1}}\right)\right]}
$$

характеризуется повторяемость ударов от режущих выступов.

При прерывистом шлифовании существует бесконечное множество резонансных состояний системы как при $\omega_{1}<\sqrt{\frac{c}{m}}$, так и при $\omega_{1}<\sqrt{\frac{c}{m}}$ (при совпадении частот или при их кратности).

Из решения (22) видно, что на величину амплитуды $A$ вынужденных колебаний превалирующее влияние оказывает импульс силы. Повторяемость действия импульсов оказывает менее значительное влияние на амплитуду вынужденных колебаний. Изменяя величину импульса силы, можно добиться изменения величины амплитуды вынужденных колебаний. С увеличением скорости шлифовального круга или с уменьшением длины режущего выступа прерывистого круга уменьшается время контакта $\tau_{1}$. Соответственнно уменьшаются импульсы силы $S=F_{0} \tau_{1}$ и амплитуда вынужденных колебаний. С уменьшением амплитуды увеличиваются фактическая глубина шлифования и толщина среза максимально выступающего зерна $H_{\max }$. 
С увеличением фактической глубины резания возрастает вероятность контакта обрабатываемого материала со связкой шлифовального круга.

Трение металла со связкой приводит к износу последней и работа шлифовального круга переходит в режим самозатачивания. Уменьшение амплитуды вынужденных колебаний говорит о том, чтоккруг не успевает отреагировать на импульс силы $S$ и система получает перемещение, равное перемещению статической силы $F_{0}$. При этом чем мньше $\tau_{1}$, тем меньше величина амплитуды $A$. Прерывистость процесса шлифования обеспечивает одновременно высокую производительность и эффективную правку круга.

Период времени работы круга между двумя режущими выступами можно выразить через угловую частоту действия импулсов $(\omega) T=2 \cdot \pi / \omega$ или через время контакта режущего выступа шлифовального круга с обрабатываемой деталью $\left(\tau_{1}\right): T=a \tau_{1}$, где $a=\left(l_{1}+l_{2}\right) / l_{1}$, где $l_{1}-$ длина режущего выступа, $l_{2}$ - протяженность впадины. После подстановки и некоторых преобразований амплитуду колебаний можно представить в виде

$$
A=\frac{F_{0} \cdot 2 \cdot \pi \cdot \sqrt{\frac{c}{m}}}{a \cdot \omega \cdot 2 \cdot c \cdot \sin \left(\pi \cdot \frac{\sqrt{\frac{c}{m}}}{\omega}\right)}=\frac{\pi \cdot X_{S T} \cdot \sqrt{\frac{c}{m}}}{a \cdot \omega \cdot c \cdot \sin \left(\pi \cdot \frac{\sqrt{\frac{c}{m}}}{\omega}\right)}
$$

где $X_{S T}=F_{0} / c$-перемещение круга в радиальном направлении от действия статического приложения силы $F_{0}$.

Из зависимости (23) следует, что при $\sin \left(\frac{\pi \cdot \sqrt{\frac{c}{m}}}{\omega}\right) \rightarrow 0$ амплитуда вынужденных колебаний $A \rightarrow \infty$.

При $A \rightarrow \infty$ обрабатываемый материал будет внедряться в рабочую поверхность круга до уровня связки, что приведет к разрушению последней. В этом случае шлифовальный круг работает в режиме самозатачивания и его режущая способность длительное время сохраняется во времени. 
Из зависимости (23) видно, что при увеличении $\omega$ до определенного значения соотношение

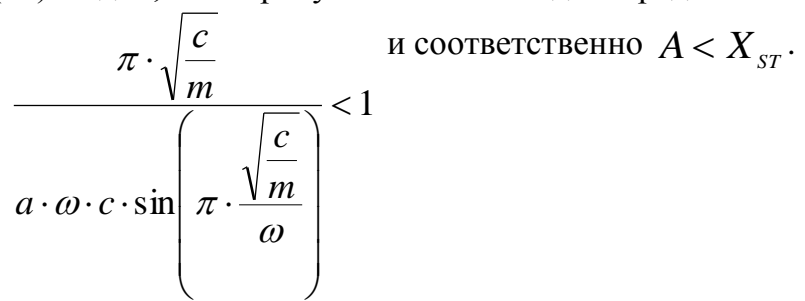

В этом и заключаетсяэффект прерывистого шлифования как метода правки круга. При этом чем больше $a$, тем выше эффект, следовательно, эффективность правки шлифовального круга возрастает с уменьшением длины режущего выступа.

После подстановки $a=\frac{l_{1}+l_{2}}{l_{1}}$ и $\omega=\frac{2 \cdot \pi \cdot V_{K R}}{l_{1}+l_{2}}$ в (23), получим

$$
A=\frac{X_{S T \cdot} \cdot \sqrt{\frac{c}{m} \cdot l_{1}}}{2 \cdot V_{K R} \cdot c \cdot \sin \left(\pi \cdot \frac{\sqrt{\frac{c}{m}}}{\omega}\right)} .
$$

Таким образом, с уменьшением длины режущих выступов $l_{1}$ (или с возрастанием их количества $n$ ) и увеличением скорости круга $V_{K R}$ уменьшается амплитуда вынужденных колебаний $A$.

На рис.1 приведены зависимоси $A=f\left(l_{1}\right)$, построеные для различных значений коэффициента прерывистости $N=\frac{l_{2}}{l_{1}}$ при шлифовании с лимбовой глубиной резания $t_{L}=0,2 \cdot 10^{-4} \mathrm{~m}$. Из графиков видно, что в исследуемом интервале протяженностей режущих выступов $0,01 \mathrm{~mm} \leq l_{1} \leq 0,10 \mathrm{~mm}$ диапазон изменения амплитуд вынужденных колебаний $A$ сужается с уменьшением коэффициента прерывистости $N$.

Из рис.1 видно, что с уменьшением протяженностей режущих выступов $l_{1}$ (при неизменном значении коэффициента прерывистости $N$ ) амплитуда вынужденных колебаний $A$ уменьшается. 


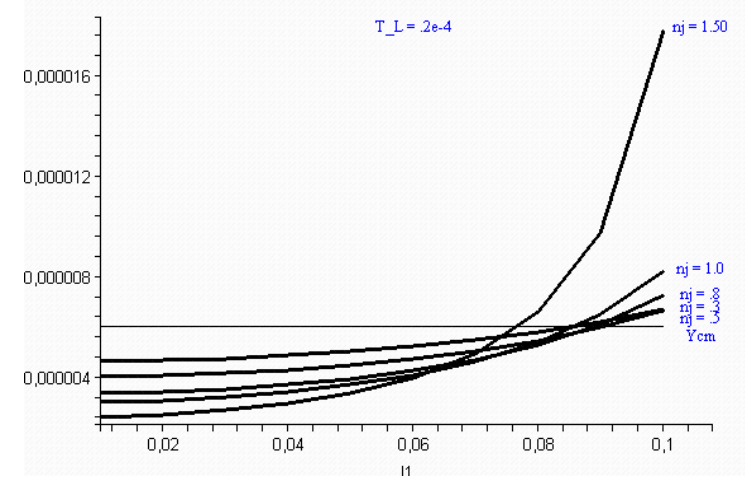

Рисунок 1 - Зависимости амплитуды вынужденных колебаний $A(m)$ от длины режущего выступа $l_{1}(m)$ при шлифовании прерывистыми кругами с различными значениями коэффициента прерывистости $N=n j=0,3 ; 0,5 ; 0,8$; 1,$0 ; 1,5$ с лимбовой глубиной резания $t_{L}=0,02 \mathrm{~mm}$.

На рис. 2 показаны зависимости амплитуды вынужденных колебаний $A$ от геометрических характеристик рабочей поверхности прерывистого шлифовального круга, построенные для двух глубин резания ( $\left.t_{L}=0,10 \mathrm{~mm}, t_{L}=0,05 \mathrm{~mm}\right)$, установленных по лимбу плоскошлифовального станка.

Зависимости $A=f(n, N)$ выглядят в виде нелинейчатых поверхностей, из анализа которых следует, что с увеличением количества режущих выступов $n$ на прерывистом круге амплитуда вынужденных колебаний $A$ уменьшается. Из графиков видно, что для исследуемого интервала чисел режущих выступов $5 \leq n \leq 40$ диапазон изменения амплитуд вынужденных колебаний сужается с уменьшением лимбовой глубины резания $t_{L}$.

Из анализа линий $A B C D$ и $K L M N$, являющихся линиями пересечения зависимостей $A=f(n, N)$ с горизонтальными плоскосями $\Pi_{1}$ и $\Pi_{2}$, можно сделать вывод, что для поддержания амплитуды вынужденных колебаний на одном и том-же уровне необходимо при увеличении коэффициента 
прерывистости $N$ уменьшать количество режущих выступов $n$ на рабочей поверхности прерывистого шлифовального круга.

В условиях прерывистого шлифования происходит периодическое изменение возбуждающей силы, приводящее к изменению жесткости упругой системы станка во времени. Колебания, обусловленные изменением такого параметра упругой системы, как жесткость, называются параметрическими колебаниями.

Так же, как и при вынужденных колебаниях, здесь можно наблюдать явления резонанса, когда частота изменения жесткости совпадает с часотой собственных колебаний.

Для выявления степени влияния геометрических параметров рабочей поверхности прерывистого круга на возможность возникновения в упругой системе плоскошлифовального станка параметрического резонанса воспользуемся условием неустойчивой работы упругой системы [9].

$$
\begin{gathered}
|L|>\frac{1+M}{2} \\
L=\frac{e^{-h\left(\tau_{1}+\tau_{2}\right)}}{h\left(k_{2}+h \sin 2 k_{2} \tau_{1}\right)}\left[k_{1}^{2} \sin k_{1} \tau_{1} \sin k_{2} \tau_{2}-\right. \\
-2 \cdot k_{1} \cdot k_{2} \cdot \cos k_{2} \tau_{1} \cdot \cos k_{1} \tau_{1} \cdot \cos k_{2}\left(\tau_{1}+\tau_{2}\right)- \\
\left.-k_{2}^{2} \sin k_{1} \tau_{1} \sin \left(2 \cdot k_{2} \tau_{1}+k_{2} \tau_{2}\right)\right] \\
M=\frac{k_{1} k_{2} e^{-2 h\left(\tau_{1}+\tau_{2}\right)} \cos \left(2 \cdot k_{2} \cdot\left(\tau_{1}+\tau_{2}\right)\right)}{h\left(k_{2}+h \sin 2 k_{2} \tau_{1}\right)}
\end{gathered}
$$

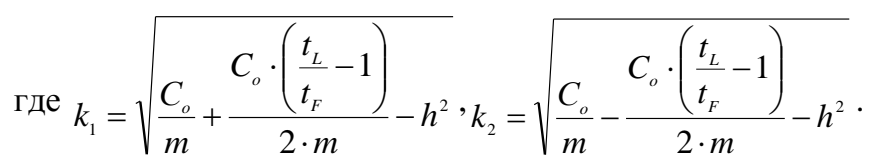

$C_{0}$ - приведенная жесткость упругой системы, $\mathrm{N} / \mathrm{m}$;

$h$ - величина, характеризующая угасание колебаний во времени;

$m-$ приведенная масса, $\left(N \cdot s^{2}\right) / m$; 
$t_{L}, t_{F}$ - глубина резания, установленная по лимбу плоскошлифовального станка и фактическая (истинная) глубина резания соответственно;

$$
\tau_{1}=\frac{l_{1}}{V_{K R}}, \tau_{2}=\frac{l_{2}}{V_{K R}} ; l_{1}, l_{2} \text { - длина режущего выступа и протяженность }
$$

впадины соответственно, $m$.

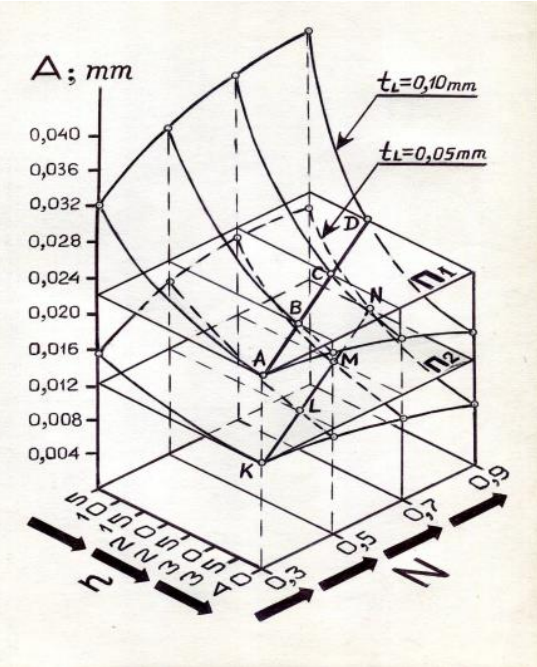

Рисунок 2 - Зависимости амплитуды вынужденных колебаний $A$, возникающих при шлифовании прерывистыми кругами с лимбовыми глубинами резания $t_{L}=0,10 \mathrm{~mm}, 0,05 \mathrm{~mm}$
от коэфициента прерывистости $N_{\text {и от количества режущх }}$
выступов $n_{\text {на абразивном инструменте }}$

По формулам (25), (26), (27) были проведены расчеты и построены зависимости $L=f(n, N)$ и $\frac{M+1}{2}=f(n, N)$ для двух значений окружной скорости круга и двух значений лимбовой глубины резания (рис.3).

Линии пересечения поверхностей, описываемых этими зависимостями, являются границами областей параметрической неустойчивости упругой системы плоскошлифовального станка.

Из сопоставления рис.3(a,c), а также рис.3(б, d) следует, что при

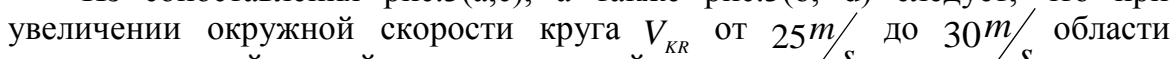
параметрической устойчивости упругой системы сҒанка смещаются в 
направлении уменьшения количества режущих выступов $n$ на прерывистом шлифовальном круге.

Из сопоставления рис.3(а,в), а также рис.3(c,d) видно, что с уменьшением лимбовой глубины резания $t_{L}$ границы областей параметрической устойчивости упругой системы станка расширяются. Из рис.3(a,б,c,d) видно, что для обеспечения параметрической устойчивости упругой системы станка необходимо при увеличении коэффициента прерывистости $N$ уменьшать количество проризей на рабочей поверхности круга $\boldsymbol{n}$.

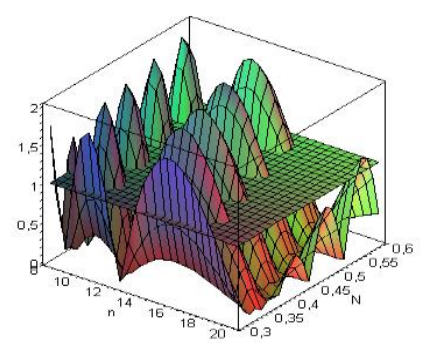

a)

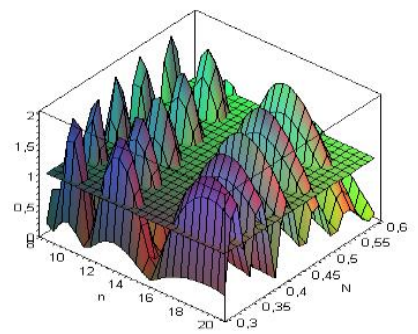

c)

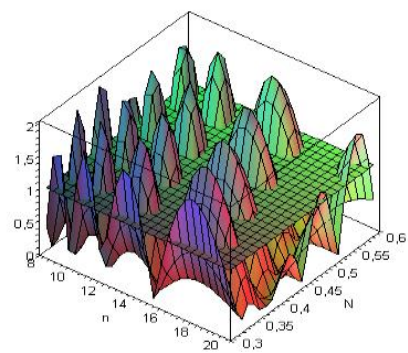

b)

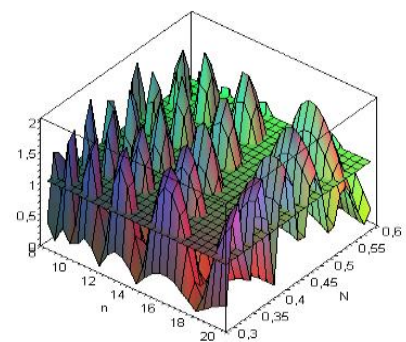

d)

Рисунок 3 - Области параметрической неустойчивости упругой системы станка при различных скоростях вращения круга $\left(V_{K R}=30 \mathrm{~m} / \mathrm{s}(\mathrm{a}, \mathrm{b}), V_{K R}=25 \mathrm{~m} / \mathrm{s}(\mathrm{c}, \mathrm{d})\right)$ и при разлиных значениях лимбовой глубины резания

$$
\left(t_{L}=0,02 m m(\mathrm{a}, \mathrm{c}), t_{L}=0,10 \mathrm{~mm}(\mathrm{~b}, \mathrm{~d})\right)
$$

\section{Выводы.}

1. Установлено, что с увеличением окружной скорости шлифовального прерывистого круга $V_{K R}$ амплитуда вынужденных колебаний $A$ уменьшается, a области параметрической устойчивости упругой системы плоскошлифовального станка смещаются в направлении уменьшения количества прорезей $n$ на рабочей поверхности абразивного инструмента. 
2. Установлено, что с увеличением количества режущих выступов $n$ на прерывистом круге амплитуда вынужденных колебаний $A$ уменьшается, а границы областей параметрической устойчивости расширяются.

3. Установлено, что в исследуемых интервалах чисел режущих выступов $5 \leq \mathrm{n} \leq 40$ и коэффициента прерывистости $0,3 \leq \mathrm{N} \leq 40$ с уменьшением лимбовой глубины резания $t_{L}$ диапазон изменения амплитуд вынужденных колебаний $A$ сужается, а границы областей параметрической устойчивости упругой системы станка расширяются.

4. Установлено, что для поддержания амплитуды вынужденных колебаний $A$ на постоянном уровне и для недопущения выхода из зоны параметрической устойчивости упругой системы необходимо при $H$ увеличении коэффициента прерывистости $N$ уменьшать количество прорезей $n$ на прерывистом шлифовальном инструменте.

5. Выявлены условия прерывистого шлифования, при которых в упругой системе плоскошлифовального станка не возникают ударный и параметрический резонансы и появляется возможность самооформления режущего микрорельефа рабочей поверхности абразивного инструмента в процессе его работы.

Список использованной литературы: 1. Новоселов, Ю.К. Стохастическая диагностика взаимодействия инструмента и заготовки при круглом наружном шлифовании /Ю.К.Новоселов, С.М.Братан//Сучасні технології у машинобудуванні: Збірник наукових праць.- Харків: НТУ «ХПІ», 2007. - С. 91-102. 2. Братан, С.М. Анализ влияния колебаний, передаваемых через фундамент станка, на качество процесса шлифования/С.М.Братан, Е.А.Владецкая//Вестник НТУ «ХПІ». -2008. -№35. - С.13-22. 3. Зубарев, Ю.М. Расчет области устойчивого процесса шлифования с учетом динамических характеристик шпиндельных устройств/ Ю.М,Зубарев, М.А. Алейникова// Инструмент и технологии. - 2005. -№21-22. - С.63-67. 4. Кохликян, С.А. О некоторых особенностях колебаний круглошлифовального станка/C.A. Кохликян, Б.С. Баласанян//Прогрессвные технологии и системы машиностроения: Сборник научных трудов. 2008. - №36. -С. 76-81. 5. Смирнов, В.A. Влияние геометрической неточности шлифовального круга и вибраций в технологической системе на изменение толщины срезаемого слоя при плоском шлифовании периферией круга / В.А. Смирнов//Вестник ИжГТУ. -2008. -№2 - - С.16-18. 6. Дианов, А.А. Образование волнистости при плоском прерывистом шлифовании периферией круга/ А.А. Дианов, Е.Ю.Татаркин, и др.//Ползуновский вестник. -2009. -Т.2. -№1- С.127-131. 7. Новиков, Ф.В. Физические и кинематические основы высокопроизводительного алмазного шлифования. - Автореф. Дис. ... докт. техн. наук. - Одесса,1995. - 360с. 8. Якимов, А.В. Качество и производительность абразивно-алмазной обработки: Учебное пособие/ A.B. Якимов, Ф.В. Новиков, и др. - Одесса: ОГПУ. - 1999. - 212с. 9. Тонконогий, В.М. Динамика прерывистого шлифования. /B.М.Тонконогий, А.А. Якимов, и др.// Резание и инструмент в технологических системах: Междунар.научн. -техн. сб. - Харьков: НТУ «ХПИ». -2015. - Вып.85. -С.288-295.

Володимир Тонконогий, Олексій Якімов, Любов Бовнегра, Ліна Майзліс, Анастасія Філановіч, Одеса, Україна

\section{ДОСЛІДЖЕННЯ ДИНАМІЧНИХ ЯВИЩ, ЩО МАЮТЬ МІСЦЕ ПРИ ПЕРЕРИВЧАСТОМ ШЛІФУВАННІ}

Анотація. Недостатня дослідженість причин виникнення небажаних коливань, які негативно
впливають на якість поверхневого шару оброблюваних деталей, стримує широке застосування
переривчастих шліфувальних кругів. Метою наукового дослідження являться визначення умов 
створення в пружній системі верстата корисних коливань, сприяючих самозагартуванню ріжучого мікрорельєфу переривчастого кола, $i$ виявлення умов виникнення ударного $i$ параметричного резонансів. Встановлено, щзо зі збільшенням окружнӧ швидкості шліфувального переривчастого кола $V_{\text {КR }}$, амплітуда вимушених коливань $A$ змениується, а області параметричної стійкості системи плоскошліфувального верстата змімуються $в$ напрямку зменшення кількості прорізей $n$ на робочій поверхні кола. Встановлено, щзо в досліджуваних інтервалах чисел ріжучих виступів $5 \leq n \leq 40$ i коефічієнта уривчастості $0,3 \leq N \leq 40$ зі зменшенням лімбової глибини різання $t_{L}$ діапазон зміни амплітуд коливань $A$ звужується, а кордони областей параметричної стійкості системи верстата розиирюються. Встановлено, щчо для підтримки амплітуди вимушених коливань А на постійному рівні $i$ для недопущення виходу із зони параметричної стійкості пружної системи необхідно при Н- збільшенні коефіцієнта уривчастості $N$ змениувати кількість прорізей $n$ на переривчастому шліфувальному інструменті. Встановлено, ш⿻о зі збільшенням кількості різальних виступів $n$ у переривчастому крузі амплітуда вимушених коливань $А$ зменшується, а межі областей стійкості розиирюються. Виявлені умови переривчастого иліфування, при яких в пружній системі плоскошліфувального верстата не виникає ударний $i$ параметричний резонанси $i$ виникає можливість самозагострювання різального мікрорельєфу робочої поверхні абразивного інструменту в проиесі його роботи.

Ключові слова: різальний виступ, переривчастий круг, пружна система верстата, ударний резонанс, параметричний резонанс, мікрорельєф робочої поверхні.

Vladimir Tonkonogyi, Alexey Yakimov, Liubov Bovnegra, Lina Maizlis, Anastasia Filanovych, Odessa, Ukraine

\title{
RESEARCH OF DYNAMIC PHENOMENA OCCURRING DURING INTERMITTENT GRINDING
}

\begin{abstract}
The purpose of scientific research is to determine the conditions for the creation in the elastic system of useful vibrations that promote self-sharpener the cutting microrelief of the intermittent circle, and the detection of the conditions for appearance the shock and parametric resonances. It was established that with the increase of the circumferential speed of the grinding discontinuous circle $V_{K R}$, the amplitude of forced oscillations A decreases, and the regions of parametrical stability of the system of the grinding machine are shifted in the direction of decreasing the number of slots $n$ on the working surface of the circle. It has been established that in the studied intervals of numbers of cutting protrusions $5 \leq n \leq 40$ and the discontinuity factor $0,3 \leq N \leq 40$, with the decrease of the limb depth of cutting $t_{L}$, the range of variation of amplitudes of forced oscillations $A$ is narrowed, and the boundaries of the regions of the parametric stability of the system of the machine are expanded. It has been established that in order to maintain the amplitude of the forced oscillations $A$ at a constant level and to prevent the exit from the parametric stability zone of the elastic system, it is necessary, when $\mathrm{H}$ increasing the factor of discontinious $N$ to decrease the number of openings on the discontinious grinding tool. It is established that with the increase in the number of cutting protrusions $n$ in a discontinuous circle, the amplitude of forced oscillations $A$ is decreasing, and the boundaries of the stability regions are expanded. Conditions of discontinuous grinding are found, where in the elastic system of the grinding machine there is no shock and parametric resonance and there is the possibility of self-sharpening of the cutting microrelief of the working surface abrasive tool during its operation.
\end{abstract}

Keywords: cutting ledge, irregular circle, elastic systems of the machine, shock resonance, self-sharpening of the cutting microrelief. 